the amount of grant the Minister will have regard to the general standards of the courses, the needs of the area, the activities of other bodies providing further education in the area and the fees paid by students". The report remarks that it is to the sense of partnership built up, over the years, between the Ministry and the responsible bodies that we must look for a solution of the difficult problem of maintaining a reasonable control over expenditure while preserving the due rights and responsibilities of the responsible bodies.

During the session under review the Minister was able to relax somewhat the severe limitations on grant-aid during the previous two sessions and, in particular, to give some assistance towards the mounting cost of tutors' salaries. Most extra-mural departments of universities at the end of the session reported a slight increase in the number of courses provided, the total of 4,302 exceeding the peak of 4,116 in $1950-51$, while the number of students increased from 78,672 in $1953-54$ to 84,752 . The increase was largest in short courses of three to nine meetings (19 per cent) and smallest $(0.9$ per cent) in tutorial classes ; sessional classes increased by 6 per cent. There was an increasing tendency, particularly in tutorial classes, to provide tutorial and sessional classes outside the traditional framework of collaboration with the Workers' Educational Associa. tion, and all this expansion has been achieved mainly with the help of part-time tutors, who increased in number from 2,342 to $2,768,1,127$ being university teachers; university lecturers appear to have been responsible for 57 per cent of the tutorial classes and 48 per cent of the sessional classes.

The extension lecture course is still an important element in most extra-mural programmes; but the majority of universities now use short extension courses in the broad field of the liberal studies as a means of interesting the general public in some aspect of university study and keeping those already interested abreast of recent developments. Such courses are often given by a team of lecturers. A variety of courses has also sprung up to provide for serious study by other kinds of student groups, particularly those with a good background of previous education. Many courses of the extension tutorial or study course type are provided in collaboration with societies or professional organizations, and an increasing proportion of extension courses is now run in this way. While some of these courses have a strong vocational appeal, all are liberal in subjectmatter and treatment. In the post-war years, however, the universities are also providing courses directed to providing specific vocational groups with information on recent advances in university studies, especially in science and technology, mostly at a postgraduate standard. A striking feature of postwar development is the increasing use being made by extra-mural departments of residential courses, while there is now a remarkable amount of coming and going between Great Britain and foreign countries in the field of adult education. As regards subjects of study, the largest increases in the number of courses have been in the physical sciences (26 per cent), religion (17 per cent), history (12 per cent) and international affairs (12 per cent); the decline in psychology (5 per cent) and geography (10 per cent) has continued, and there has been a sharp contraction ( 31 per cent) in government. The demand for history is mainly for local history or archæology, and the study of languages appears to be on the increase. Interest in the social studies is much less marked, and the substantial increase in science courses is largely vocational.

Besides the Ashby report and the new regulations, the Council discusses the report on broadcasting and adult education prepared by $\mathrm{Mr}$. Maurice Bruce and is concerned about the provision of books to adult classes. Its own inquiry in England and Wales has indicated that all thirteen universities and three of the eight university colleges have their own extramural libraries, usually administered separately, whether or not they are part of the university or college library. Issues to book boxes ranged between 2,000 and 10,000 volumes a year, and expenditure between $£ 200$ and $£ 800$ a year, with substantially higher figures for London and Oxford. Five of the sixteen extra-mural libraries supplied 90 per cent or more of the books required by classes; three between 70 and 90 per cent; and three between 50 and 70 per cent. In four instances $20-50$ per cent of the supply came from the National Central Library and few libraries did not make some use of the National Central Library.

\section{THE NATIONAL VEGETABLE RESEARCH STATION OPEN DAY}

$T$

THE first open day of the National Vegetable Research Station was held on June 5 at Wellesbourne, Warwickshire, when visitors saw the progress made in the development and work of this Station. Field experiments were on view, and there were exhibits of various aspects of the research in progress.

The Plant Breeding Section illustrated how it is using inbreeding, followed by the crossing of inbred lines, in an attempt to produce hybrid varieties of Brussels sprouts having improvements in uniformity, yield and other characters over ordinary varieties. Male sterility is being used as a helpful tool in this work, as it is also with onions, in the production of hybrid seed. The cause of deterioration of varieties of brassicas is also being investigated. $F_{3}$ progenies from crosses between lettuce varieties and a wild species, Lactuca altaica Fisch and Mey, which showed little attack by mosaic virus, were exhibited. These progenies were raised from the small proportion of $F_{2}$ plants which remained mosaic-free when grown in an epidemic of the disease. Stages in the process of breeding a non-bolting, high-quality variety of red beet having single-seeded fruits were shown, also work in the production of asparagus which should give only male plants from seed instead of the usual 1 : 1 ratio of male and female. Breeding material of forcing radish, spring cabbage and early cauliflower was also exhibited.

Long-term field experiments were seen which provide the Chemistry Section with material for its soil studies and work on the nutrition of vegetables. Descriptions were given of the effects of deep and shallow ploughing and of rotavating ; of the application of fertilizers and farmyard manure at different depths, rates and times ; and of inorganic and organic nitrogenous fertilizers on various rotations of vegetables. A demonstration was given of the restriction in development of the root system of peas brought about by soil compaction following certain cultivation treatments. Results from the use of chromatography in 
the study of the biochemistry of vegetables were shown, and this technique is being used in an investigation of a virus inhibitor present in rhubarb sap. A soil map of the Station's 280 acres was on view together with soil monoliths.

The Irrigation Section demonstrated the water-loss by transpiration and evaporation from cauliflowers during bright sunshine and showed that it was equivalent to about 200 gallons an hour per acre of growing crop. Different soil moisture meters were displayed together with data on their performance, and a prototype gauge was shown which indicated the minimum amount of water required to bring soil under a crop to field capacity ; this gauge takes into account rainfall and water loss by transpiration and evaporation. The accuracy and efficiency of various techniques for measurement of leaf area were demonstrated, and the effects of different soil moisture conditions on growth, yield and quality of vegetables were shown.

The Entomology Section showed the life-cycle of the cabbage root fly, the damage it causes to brassica crops, and the most effective methods of controlling it. Illustrations were given of some natural predators of the pest and of insecticidal treatments which may destroy the predators, thus leaving a clear field for severe attack by the pest. The biology of the carrot fly, a serious pest of carrots, parsnips and parsley, was shown together with methods of insecticidal control involving seed dressings followed sometimes by supplementary sprays. A tasting panel assesses the degree of taint or off-flavour of carrots which may be brought about by certain insecticidal treatments. The life-history of the pea moth and the per aphid and their control by DDT were demonstrated. Work in progress on the biology and control of lettuce root aphid was shown; but the recent discovery of varieties resistant to attack appears to offer the best solution of the problem.

The Pathology Section illustrated the life-history of the fungus which causes crook root disease of watercress, and the promising results obtained for the control of the disease by adding to the cress beds material which liberates minute quantities of zinc. It also showed the life-history of the bacterial pathogen found to cause the silvering disease of red beet seed crops, and the degree of control obtained by seed treatment with streptomycin. Methods of eliminating sources of infection by the fungus Didymella on outdoor tomato crops, and the effects of fungicides in checking the spread of the disease were exhibited. Parsnip canker has been found not to be invariably associated with damage by carrot fly larvae, and a fungus which can cause the disease has been isolated. Work in progress on virus diseases of rhubarb and watercress was exhibited, also some varieties of mint found to have resistance to mint rust. Results of studies on the control of Botrytis in lettuce by cul. tural methods and by fungicides were also shown.

The Weeds Section demonstrated techniques used in its ecological studies which are providing fundamental information necessary for the development of weed control in vegetable crops by cultural and chemical means. Changes in weed populations brought about by different manurial, cultivation and rotation treatments were described, and the effects of competition between weeds and vegetable crops at different stages of growth were shown. A demonstra. tion was given of the effects of dinoseb (ammonium), dinoseb (amine), and a substituted phenoxybutyric acid MCPB as herbicides for market garden peas, also the degree of tolerance of different varieties to the sprays. The residual pre-emergence herbicide CMU was shown also to be useful for the control of annual weeds in asparagus beds.

The Statistics Section carries out investigations with the object of improving the efficiency of field experiments with vegetables, in addition to its advisory work for other Sections and for outside bodies on the design and analysis of experiments. In studies on the origin of experimental errors in the field, the effects of different methods of sowing peas, and of using different size grades of cauliflower plants when planting in the field were demonstrated. The economics of spacing of glasshouse and frame lettuce were illustrated, and work in progress was shown on the genetics of continuous variation in French beans.

J. Phil

\section{NOCTURNAL TEMPERATURE PROFILE ABOVE BARE SOIL ON CLEAR NIGHTS}

T has long been established that in the lowest few 1 hundred feet of the atmosphere there is on calm clear nights on the whole an inversion (that is, temperature increases with height), presumably determined by radiation of heat from the ground. The observations of Johnson and Heywood at Leafield (Meteorological Office Geophysical Memoir 77 ; 1938) showed that this inversion comes into being remarkably suddenly about sunset. As part of this structure it was supposed that the lowest temperature was normally to be found on the ground surface itself, the air above being cooled by loss of heat to the ground by conduction and convection. Doubts as to whether this was always so have been expressed for a long time. J. Glaisher in 1847 reported that on all clear nights in the year 1843-44 the mean minimum temperature on short grass was $0.8 \mathrm{deg}$. F. higher than that recorded 1 in. above the top of the grass. Many other workers have found the tempera. ture on radiation nights to be sometimes lower a few inches above the surface than on the surface; but such a structure has not been regarded by meteorologists as a regular feature.

J. V. Lake, of the University of Reading, has recently described in the Quarterly Journal of the Royal Meteorological Society (April 1956) the results of temperature observations with the most up-to-date instruments in the lowest few feet over bare soil on calm clear nights. Lake measured temperatures with both minute thermistor beads and with ordinary unscreened alcohol-in-glass minimum thermometers at heights of $0 \cdot 1,0 \cdot 5,1 \cdot 5,2 \cdot 5,3.5$ and 54 in. The results were all the same: minimum temperature at $2-3$ in. above the surfare, with an inversion above and a super adiabatic lapse-rate below. For completeness the surface radiation temperature was measured with a spirit thermometer. On the early morning of March 22, 1955, the surface radiation temperature was $21^{\circ} \mathrm{F}$, and the temperatures at the higher levels specified above were, in the mean of fifty-two observations at each height, respectively : $18 \cdot 6,17 \cdot 3,16 \cdot 6,16 \cdot 4,16 \cdot 8$ and $18 \cdot 4^{\circ} \mathrm{F}$. The standard deviations of the observations were 0.93 deg. F. at $0 \cdot 1 \mathrm{in}$. and $0 \cdot 35-0 \cdot 46 \mathrm{deg}$. F. at higher levels.

The temperature profile below the minimum is of the kind which occurs over a surface strongly heated 